Check for updates

Cite this: RSC Adv., 2019, 9, 32296

\title{
Assembly of gold nanoparticles using turnip yellow mosaic virus as an in-solution SERS sensor $\dagger$
}

\author{
Ha Anh Nguyen, ${ }^{a}$ Isabelle Jupin, ${ }^{b}$ Philippe Decorse, ${ }^{\text {a }}$ Stephanie Lau-Truong, ${ }^{a}$ \\ Souad Ammar (ID a and Nguyet-Thanh Ha-Duong (D) *a
}

A common challenge in nanotechnology is the conception of materials with well-defined nanoscale structure. In recent years, virus capsids have been used as templates to create a network to organize 3D nano-objects, building thus new functional nanomaterials and then devices. In this work, we synthetized 3D gold nanoclusters and we used them as Surface Enhanced Raman Scattering (SERS) sensor substrates in solution. In practice, gold nanoparticles (AuNPs) were grafted on turnip yellow mosaic virus (TYMV) capsid, an icosahedral plant virus. Two strategies were considered to covalently bind AuNPs of different sizes $(5,10$ and $20 \mathrm{~nm}$ ) to TYMV. After purification by agarose electrophoresis and digestion by agarase, the resulting nano-bio-hybrid AuNP-TYVM was characterized by different tools. Typically, dynamic light scattering (DLS) confirmed the grafting through the hydrodynamic size increase by comparing AuNPs alone to AuNP-TYMV (up to 33, 50 and $68 \mathrm{~nm}$ for 5, 10 and $20 \mathrm{~nm}$ sized AuNPs, respectively) or capsids alone $(28 \mathrm{~nm})$. Transmission electronic microscopy (TEM) observations revealed that AuNPs were arranged with 5-fold symmetry, in agreement with their grafting around icosahedral capsids. Moreover, UV-vis absorption spectroscopy showed a red-shift of the plasmon absorption band on the grafted AuNP spectrum $(530 \mathrm{~nm})$ compared to that of the non-grafted one $(520 \mathrm{~nm})$. Finally, by recording in solution the Raman spectra of a dissolved probe molecule, namely 1,2-bis(4-pyridyl)ethane (BPE), in the presence of AuNP-TYVM and bare AuNPs or capsids, a net enhancement of the Raman signal was observed when BPE is adsorbed on AuNP-TYVM. The analytical enhancement factor (AEF) value of AuNP-TYMV is 5 times higher than that of AuNPs. These results revealed that AuNPs organized around virus capsid are able to serve as in-solution SERS-substrates, which is very interesting for the conception of ultrasensitive sensors in biological media.

\author{
Received 2nd October 2019 \\ Accepted 5th October 2019 \\ DOI: $10.1039 / \mathrm{c} 9 \mathrm{ra} 08015 \mathrm{e}$ \\ rsc.li/rsc-advances
}

\section{Introduction}

Nanomaterials sciences have attracted an increasing interest in the bottom-up synthesis of functional structures based on biomolecules as nanoscale building blocks (nucleic acid, proteins, carbohydrates and lipids), because of their ability to self-assemble and form systems with great structural diversities. ${ }^{1}$ Conjugated with inorganic or organic nano-objects, the resulting bio-hybrid materials present wide-ranging applications, such as bioimaging, biosensing, catalysis, energy conversion etc. $^{2-4}$ Viruses are increasingly being used in nanotechnology as 3D scaffolds. ${ }^{5-11}$ Their capsids are composed of self-assembled protein subunits, and are uniform in shape and size (20-200 nm in diameter). They also show structural and chemical stability, monodispersity, and ease of production.

${ }^{a}$ ITODYS, CNRS, UMR 7086, Université de Paris, 15 Rue J-A de Baïf, F-75013 Paris, France. E-mail: thanh.haduong@univ-paris-diderot.fr; Tel: +33-1-57-27-72-39

${ }^{b}$ Laboratory of Molecular Virology, Institut Jacques Monod, CNRS, Université de Paris, France

$\dagger$ Electronic supplementary information (ESI) available. See DOI: 10.1039/c9ra08015e
Genetic or chemical modification of the capsid protein subunits leads to the functionalized outer surface which allows 3D organization of nanoparticles (NPs). Moreover, plant viruses show lack of pathogenicity in humans and animals.

Turnip yellow mosaic virus (TYMV) is a non-enveloped plant virus of $28 \mathrm{~nm}$ of diameter. Its structure has been resolved by X-ray crystallographic analysis ${ }^{\mathbf{1 2}}$ and has been studied by electron microscopy using negative staining: ${ }^{13}$ Its genome is composed of a single-stranded RNA molecule of 6318 bases which is protected by a proteinaceous capsid consisting of 180 identical coat proteins of $20133 \mathrm{Da}$, arranged in a $T=3$ icosahedron. ${ }^{12}$ TYMV is stable within a wide diversity of conditions, including temperature from $4{ }^{\circ} \mathrm{C}$ to $60{ }^{\circ} \mathrm{C}, \mathrm{pH}$ value from 4 to 10 , and in up to $50 \%$ organic solvent. ${ }^{14}$ Furthermore, Wang's group showed that TYMV capsid can withstand a variety of reaction conditions, such as EDC/NHS amidation reaction, or $\mathrm{Cu}(\mathrm{I})$ catalyzed "click" chemistry. ${ }^{\mathbf{1 4 , 1 5}}$ Indeed, this group succeeded in grafting fluorescent molecules and peptides onto TYMV surface without affecting the assembly of the capsid. More recently, Cho's group showed that empty TYMV conjugated with cell penetrating peptide can be efficiently used as delivery cargo to mammalian cells. ${ }^{16}$ 
Colloidal gold nanoparticles (AuNPs) are some of the most studied nanomaterials. The size and shape of these objects can be easily controlled to obtain AuNPs in the range of 1 to $150 \mathrm{~nm}$ with different morphologies that offer unique chemical, electrical and optical properties. In addition to the gold core, a protective coating that surrounds the core can also be modified to control particle stability, solubility and interaction with the biological environment. ${ }^{17}$ Because of their low toxicity, AuNP have been exploited for a wide variety of biomedical applications, ${ }^{18,19}$ including plasmonic photothermal therapy, ${ }^{20}$ gene and drug delivery, ${ }^{21}$ two photon bioimaging, ${ }^{22}$ cancer radiotherapy ${ }^{17}$ and plasmonic biosensing. ${ }^{23}$ Surface Enhanced Raman Spectroscopy (SERS) is a surface sensitive technique that involves inelastic scattering of incident laser energy on a surface molecule, resulting in vibrational spectral peaks of the molecule. When the analytes, as different as chemical or biological compounds, were adsorbed onto a rough plasmonic metal, their Raman signals, are enhanced, allowing their rapid detection even as traces. Such a feature is particularly useful for the conception of drugs and pharmaceuticals, ${ }^{24,25}$ peptides and proteins, ${ }^{26} \mathrm{DNA}^{27}$ or even microorganisms ${ }^{28,29}$ sensors.

SERS sensitive regions (or "Hot spots") are created with highly-ordered assembly of AuNP. Icosahedral viruses are then good candidates for the bottom-up synthesis of SERS substrates. Icosahedral AuNP arrangements are not at all easy to achieve by conventional chemical surface engineering. Most of the time planar or completely spherical structures are obtained by such assembling tool. ${ }^{30-32}$ Grafting AuNPs to the surface of the icosahedral-shaped cowpea mosaic virus (CPMV) has been already achieved and the resulting leading to AuNP-CPMV biohybrids have been successfully used as DNA SERS sensors. ${ }^{33}$ A mutation on the coat protein allowed the substitution by cysteine amino acid residue at the surface of the capsid, offering several positions to covalently bond AuNPs to the CPMV surface. ${ }^{34-36}$ Surprisingly, whereas the literature is rich on the description of such AuNP based bio-hybrids, investigations on their use as SERS substrates for chemical sensing are seldom. For instance, several reports exist on the use of the rod-shaped plant virus Tobacco mosaic virus (TMV), and its various mutants, as efficient templates for the nano-fabrication gold nanowires or superlattices wires, ${ }^{37,38}$ nanotubulars ${ }^{39}$ or nanorings ${ }^{40}$ but nothing is said on the ability of the resulting biohybrids to be used as SERS sensors in solution.

In this context, the present work wants to fill the gap between what exist in the literature in terms of nano-biohybrid fabrication and what one can do around their SERS properties for the design of original sensors. Focusing on the TYMV virus, we describe here the preparation of a set of AuNP-TYMV hybrids, their full structural characterization and their evaluation, and as a proof of concept, through preliminary assays, as in-solution SERS substrates. Interestingly, we used two alternative chemical strategies to covalently attach AuNP to TYVM. The efficiency of these strategies to build robust nano-bio-hybrids was also compared. The first consists on forming an amide bond between the capsid protein of the virus particle and AuNP surrounded by amine groups (Fig. 1). The second results from the modification of
TYMV capsid, so that its surface harbours thiol groups (Fig. 1). Indeed, TYMV is free from cysteine residues at its surface and a thiol grafting is specifically required to make it valuable for AuNP attachment by covalent S-Au bonding [Fig. 1].

\section{Materials and methods}

\section{Turnip yellow mosaic virus extraction and purification}

Chinese cabbage (Brassica pekinensis cv. Granaat) plants were grown and inoculated with TYMV as previously described. ${ }^{\mathbf{4 1}}$ Virus was extracted and purified by differential centrifugation. ${ }^{\mathbf{4 2}}$ Infected leaves were homogenized using a Waring Blendor in $5 \mathrm{~mL} \mathrm{~g}^{-1}$ of $10 \mathrm{mM}$ Tris- $\mathrm{HCl} \mathrm{pH} \mathrm{7.0.} \mathrm{The} \mathrm{mixture} \mathrm{was} \mathrm{centri-}$ fuged at $3200 \times g$ for $30 \mathrm{~min}$ at $4{ }^{\circ} \mathrm{C}$, the supernatant was collected and adjusted to $\mathrm{pH} 4.8$ with acetic acid. After overnight incubation at $4{ }^{\circ} \mathrm{C}$, the sample was centrifuged in the same conditions. The supernatant was collected and centrifuged at $165000 \times g$ in a Type 70 Ti rotor for 3 hours at $4{ }^{\circ} \mathrm{C}$. The pellet containing virus particles was then resuspended in $10 \mathrm{mM}$ potassium phosphate buffer $\mathrm{pH}$ 7.4, and centrifuged at $15000 \times g$ for $15 \mathrm{~min}$ at $4{ }^{\circ} \mathrm{C}$. The supernatant was subjected to another cycle of high speed/low speed centrifugation, filtered on $0.22 \mu \mathrm{m}$ and virus concentration was measured using an absorption coefficient of $8.6 \mathrm{~L} \mathrm{~g}^{-1} \mathrm{~cm}^{-1}$ at $260 \mathrm{~nm}$. Virus particles were stored for months at $4{ }^{\circ} \mathrm{C}$.

The size of the capsid was measured by Dynamic Light Scattering (DLS) in low-form semi-micro plastic cuvettes (with 4 clear sides and $1 \mathrm{~cm}$ path-length) with a Malvern Nano Zetasizer, and confirmed by Transmission Electron Microscope (TEM) (JEOL JEM 2010 UHR), operating at $200 \mathrm{kV}$. After staining with uranyl acetate, the samples were prepared by evaporating a drop of stained virus in water on a carbon-coated copper grid. Finally, the isoelectric point was determined by $\zeta$ potential measurements performed on Malvern Nano Zetasizer $(100 \mu \mathrm{g}$ $\left.\mathrm{mL}^{-1}\right)$. PDI value and autocorrelation curves are shown in ESI section (Table S1 and Fig. S1†).

\section{Gold nanoparticles synthesis and functionalization}

AuNP of $5 \mathrm{~nm}$ were purchased from Sigma-Aldrich. The AuNP of 20 and $10 \mathrm{~nm}$ were synthetized according to the procedure described by Turkevich et $a l^{43,44}$ Briefly, $50 \mathrm{~mL}$ of a solution of chloroauric acid $\left(\mathrm{HAuCl}_{4}\right)$ at $2.65 \mathrm{mM}$ is diluted to $200 \mathrm{~mL}$ of boiling water. $\mathrm{HAuCl}_{4}$ is reduced by the addition of $25 \mathrm{~mL}$ of trisodium citrate at $20 \mathrm{mM}$. The mixture was allowed to stir and boil during $20 \mathrm{~min}$. In this procedure, spherical AuNP of $20 \mathrm{~nm}$ are obtained with absorption maximum at $520 \mathrm{~nm}$. Those of $10 \mathrm{~nm}$ were obtained by adding $15 \mathrm{~mL}$ of trisodium citrate at $69.36 \mathrm{mM}$ to $150 \mathrm{~mL}$ of boiling solution $\mathrm{HAuCl}_{4}$ at $1.11 \mathrm{mM}$, and then let the mixture 15 min under stirring and boiling.

AuNP were functionalized by adding 1-amino-6-hexanethiol (500 coating molecules for 1 AuNP).

\section{Gold nanoparticles characterization}

Size and shape of AuNP were measured by DLS and TEM using the same equipments than those cited previously. The DLS 

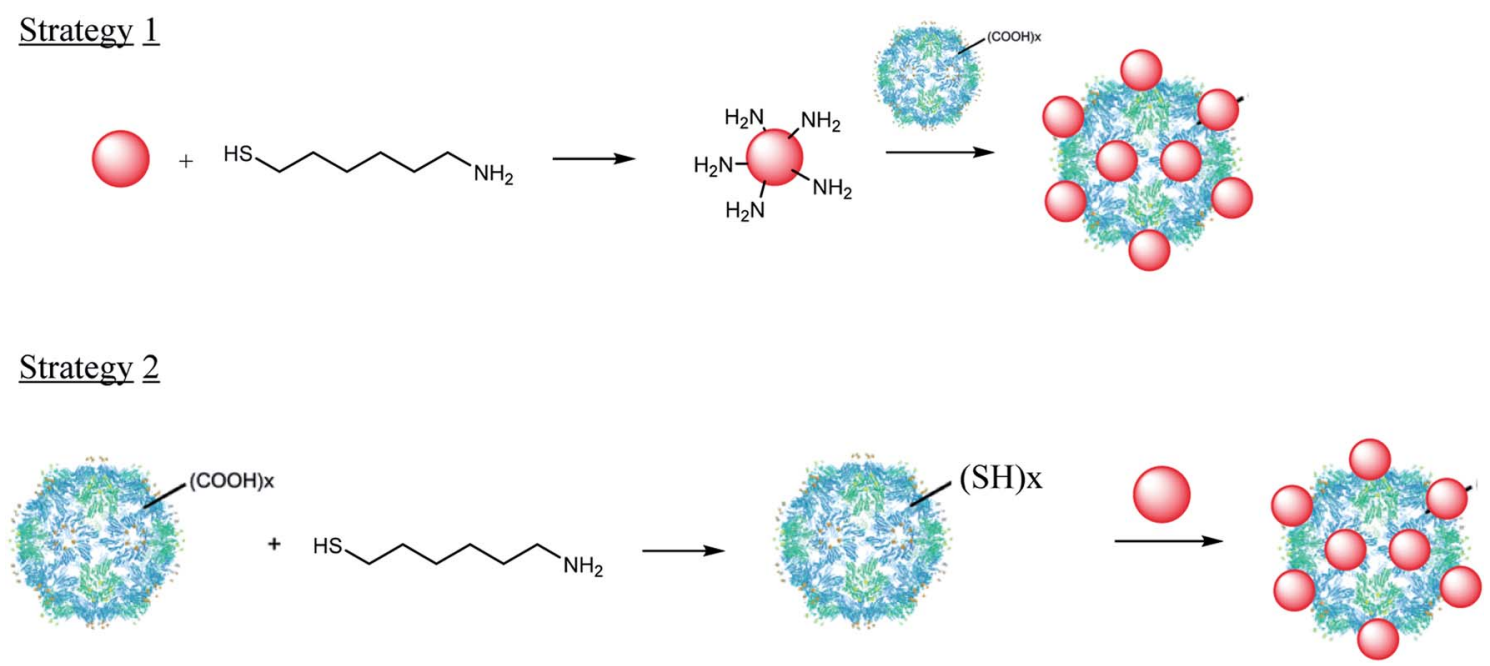

Fig. 1 Schematic representation of the two chemical strategies used to bond AuNP to TYVM.

experiments were performed in solution just after the synthesis without any concentration steps. Samples for TEM experiments were prepared by evaporating drops of solution in water on carbon-coated copper grid.

The surface composition was investigated by X-ray Photoelectron Spectroscopy (XPS) using a KAlpha ${ }^{+}$system (Thermo Fisher Scientific, East-Grinstead, UK) equipped with a microfocused and monochromatic $\mathrm{Al} \mathrm{K} \alpha \mathrm{X}$-ray source $(1486.6 \mathrm{eV}, 12$ $\mathrm{kV}$ ) with a X-ray spot size of $400 \mu \mathrm{m}$. The spectrometer pass energy was set to 150 and $40 \mathrm{eV}$ for the survey and the narrow (high resolution-HR) regions, respectively. The spectra were calibrated against the $(\mathrm{C}-\mathrm{C} / \mathrm{C}-\mathrm{H}$ C) $\mathrm{C} 1 \mathrm{~s}$ component set at $285 \mathrm{eV}$. The chemical composition was determined with Avantage software (version 5.9902), by using the manufacturer sensitivity factors. The samples were prepared by evaporating drops of solution in water on the conducting side of ITO plaques.

Absorption spectra of AuNP were performed at $25 \pm 0.5^{\circ} \mathrm{C}$ on a Cary 4000 spectrophotometer equipped with Pelletierthermostated cell-carriers.

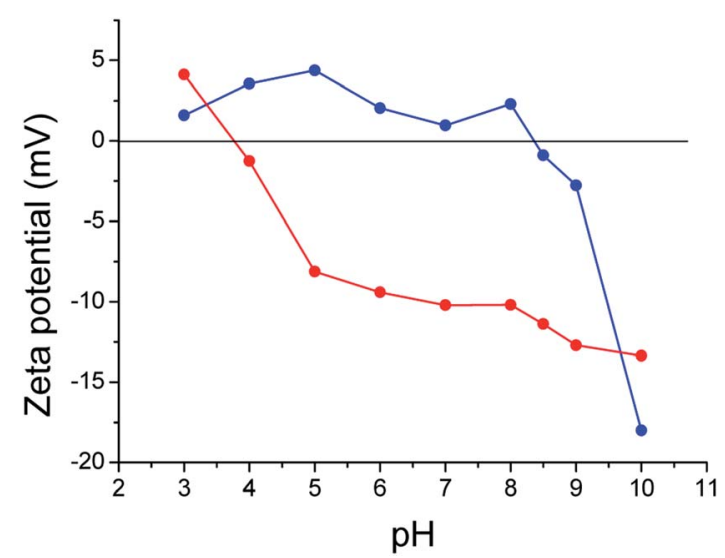

Fig. 2 Variation of $\zeta$ potential against $\mathrm{pH}$ of TYMV (red) and TYMV coated with 6 -aminohexane-1-thiol (blue).

\section{Grafting of AuNP to TYMV}

Two different strategies of synthesis were developed based on EDC activated amidation reaction (Fig. 1). The number of TYMV particles was calculated from the molecular mass of the capsid (3.6 MDa) and that of AuNP from the mass of $\mathrm{AuHCl}_{4}$ introduced during the synthesis and the diameter of the AuNP (See ESI $\dagger)$. For each strategy, $25 \mu \mathrm{g}$ of TYMV $\left(\sim 0.4 \times 10^{13}\right.$ TYMV particles) was activated for grafting with $20 \mathrm{~mL}$ of 20 nm-AuNP $\left(\sim 0.4 \times 10^{13}\right.$ particles per $\left.\mathrm{mL}\right), 10 \mathrm{~mL}$ of $10 \mathrm{~nm}-$ AuNP $\left(\sim 1.2 \times 10^{13}\right.$ particles per $\left.\mathrm{mL}\right)$ or $5 \mathrm{~mL}$ of $5 \mathrm{~nm}$-AuNP $\left(\sim 5.5 \times 10^{13}\right.$ particles per $\left.\mathrm{mL}\right)$, respectively. In practice, for the first strategy, EDC (1-ethyl-3-(3-dimethylaminopropropyl) carbodiimide hydrochloride, $2 \mathrm{mM}$ ) was added to activate the carboxyl group on the surface of TYMV capsid $(100 \mu \mathrm{g}$ $\mathrm{mL}^{-1}$ ) and the solution was incubated at room temperature (RT) for $15 \mathrm{~min}$, followed by the addition of NHS ( $N$-hydroxysuccinimide, $5 \mathrm{mM}$ ). After $30 \mathrm{~min}$, the pre-activated carboxylic TYMV was mixed with AuNP functionalized with 1-amino6-hexanethiol as a primary amine source and allowed to react

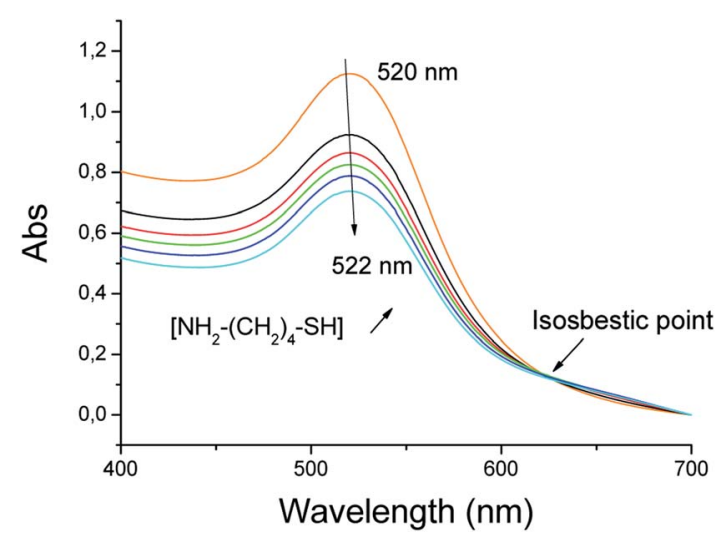

Fig. 3 Absorption spectra of AuNP of $20 \mathrm{~nm}$ in the presence of increasing concentrations of 6-amino-hexane-1-thiol. 
at RT in the dark overnight. For the second, thiol groups were introduced onto TYMV capsid by the grafting of 1-amino-6hexanethiol to the pre-activated carboxylic TYMV with the same procedure as in strategy 1 . AuNP were then added and incubated for 24 hours to form covalent bond between gold and thiol groups, leading to the grafting of AuNP to TYMV.

Whatever the grafting strategy, the obtained mixtures were concentrated to $200 \mu \mathrm{L}$ in a $100 \mathrm{k}$ MWCO centrifugal concentrator (Vivaspin ${ }^{\circledR} 20$, Sigma-Aldrich). Each concentrated sample was then mixed with $10 \mu \mathrm{L}$ of thioctic acid (TA, $20 \mathrm{mM}$ in ethanol) and $20 \mu \mathrm{L}$ of $10 \times$ TBE buffer (890 mM Tris-base, $890 \mathrm{mM}$ boric acid, $20 \mathrm{mM}$ EDTA, $\mathrm{pH}$ 8.3) and incubated in Eppendorf tubes at RT for $30 \mathrm{~min}$. After the TA treatment, the mixture was transferred to a small-sized 100k MWCO concentrator (Vivaspin ${ }^{\circledR}$ 500, Sigma-Aldrich) and concentrated to 60 $\mu \mathrm{L}$. Both centrifugation steps were performed using a fixed angle centrifuge at $200 \times g$, at $15{ }^{\circ} \mathrm{C}$.

Separation and purification of the resulting nano-biohybrids were performed by agarose electrophoresis. ${ }^{36}$ Prior to electrophoresis, $6 \mu \mathrm{L}$ of $50 \%$ glycerol in water was mixed with the sample. $33 \mu \mathrm{L}$ of the mixture was loaded per well in a $1 \%$ low-melting agarose (Thermo Fisher Scientific) $/ 1 \times \quad$ TBE electrophoresis gel. The gel was run at $70 \mathrm{~V}\left(5 \mathrm{~V} \mathrm{~cm}^{-1}\right)$ in $1 \times$ TBE until achieving a clear separation between free AuNP and TYMV grafted with AuNP bands that could be observed visually due to the red color of the AuNP. The band corresponding to grafted TYMV was cut off from the gel, transferred to a $2 \mathrm{~mL}$ Eppendorf tube and incubated at $70{ }^{\circ} \mathrm{C}$ in an Eppendorf Thermomixer R Mixer for $10 \mathrm{~min}$ for melting the agarose gel. The tube was then cooled down to $42{ }^{\circ} \mathrm{C}$ and equilibrated for 5 min before the addition of $\beta$-agarase (Thermo Fisher Scientific, $1 \mathrm{U}$ of enzyme per $100 \mathrm{mg}$ of $1 \%$ agarose gel) for the enzymatic digestion of agarose at $42{ }^{\circ} \mathrm{C}$ for 4 hours. The sample was then cooled down gradually and incubated overnight at RT. Grafted TYMV in digested agarose could be stored at $4{ }^{\circ} \mathrm{C}$ for weeks. For further characterization including absorption spectrometry, DLS, zeta-potential, TEM and XPS (Fig. S2 $\dagger$ ), the sample was washed with water using a $100 \mathrm{k}$ MWCO concentrator to remove the oligosaccharides. Absorption spectra, DLS and XPS measurements of the purified materials were performed as described in the previous parts of AuNP and virus characterizations. The samples for TEM were prepared by placing a drop of the hybrid materials on a carbon-coated copper grid for $2 \mathrm{~min}$. To avoid aggregation (a)

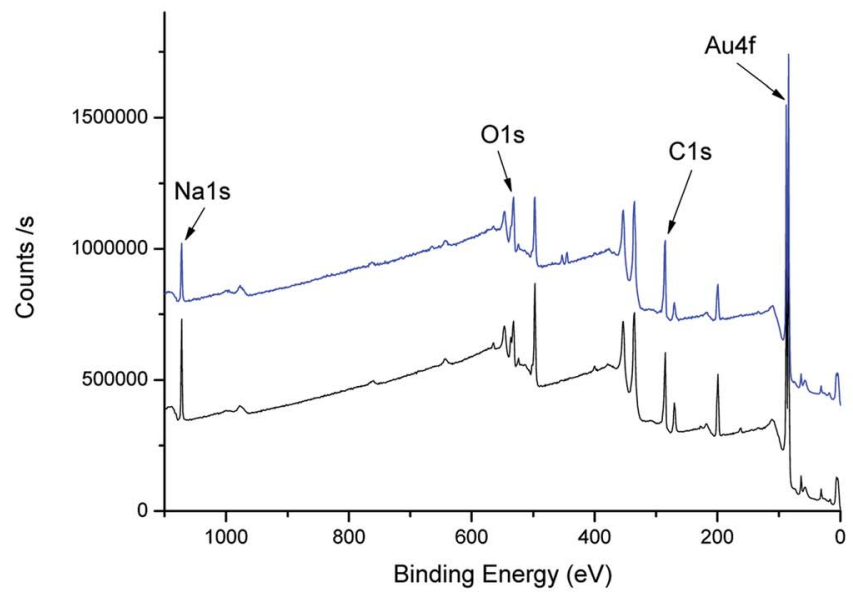

(c)

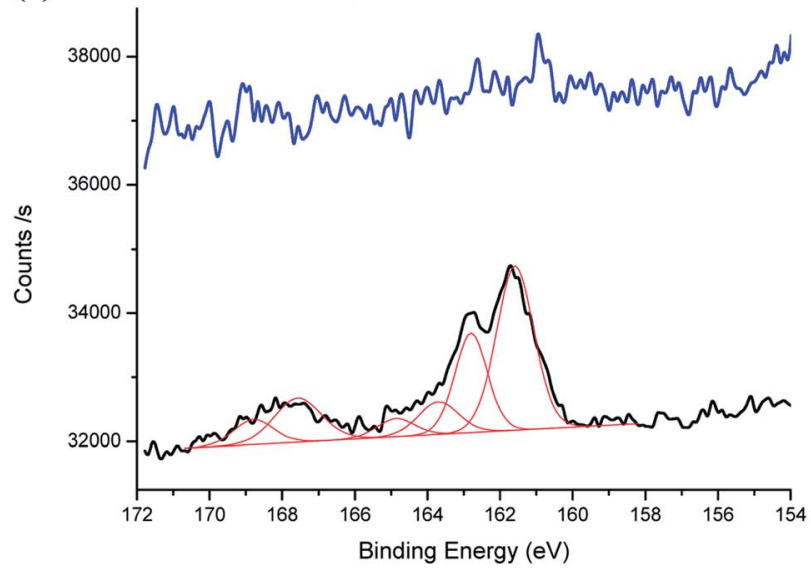

(b)

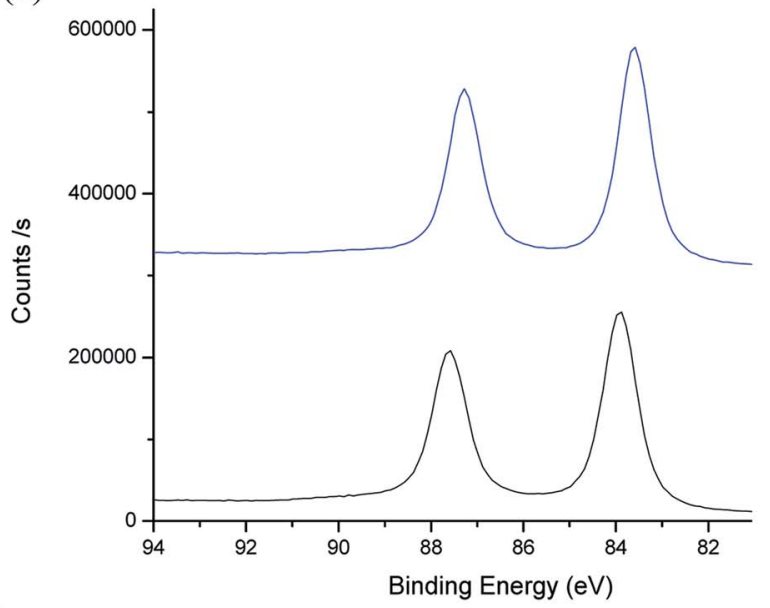

(d)

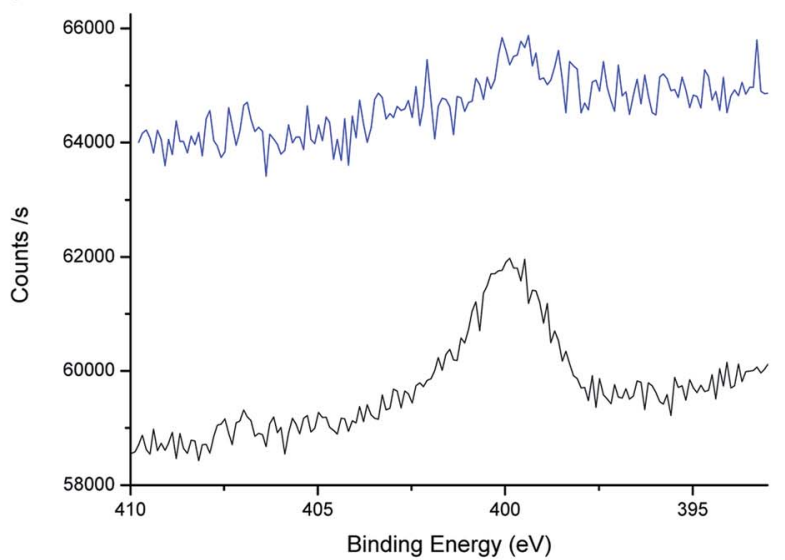

Fig. 4 XPS spectra of AuNP (blue) and AuNPa6-aminohexane-1-thiol (black): (a) survey spectra, (b) HR-Au 4f region, (c) HR-S 2p region and deconvolution (red) and (d) HR-N 1s region. 


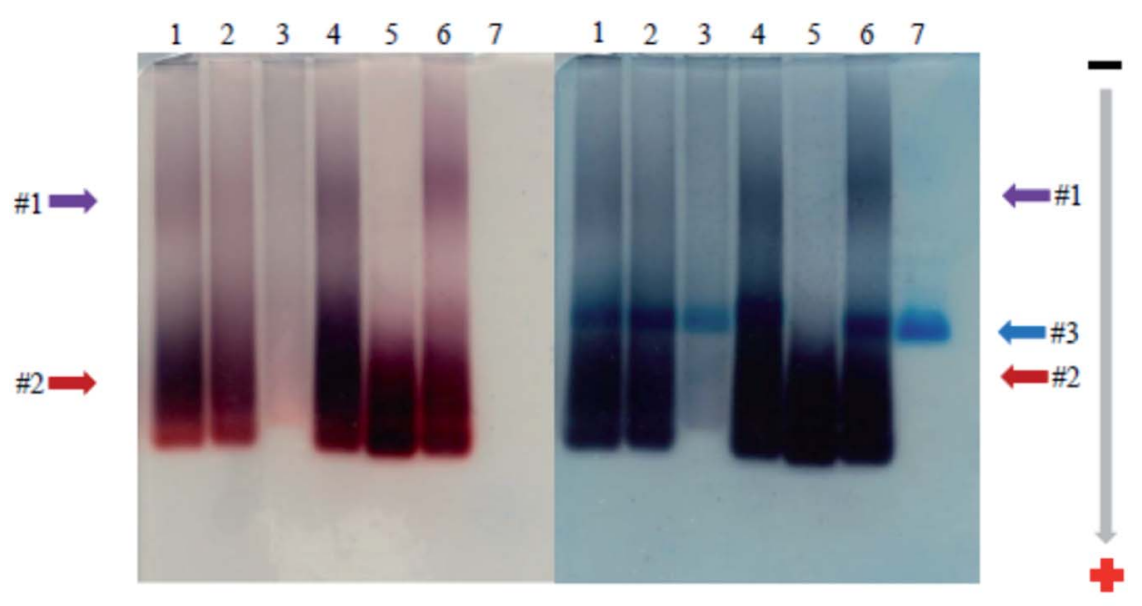

(a)

(b)

Fig. 5 Agarose electrophoresis of TYMV grafted with AuNPs in different experimental conditions before (a) and after (b) staining with Coomassie

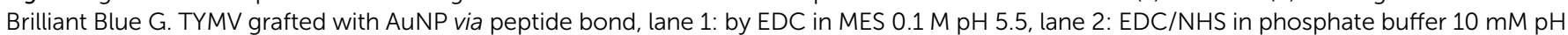
7.0, lane 3: EDC in phosphate buffer $10 \mathrm{mM} \mathrm{pH} \mathrm{6.0,} \mathrm{lane} \mathrm{4:} \mathrm{EDC} \mathrm{in} \mathrm{acidic} \mathrm{water} \mathrm{pH} \mathrm{6.0,} \mathrm{respectively;} \mathrm{lane} \mathrm{5:} \mathrm{free} \mathrm{AuNP;} \mathrm{lane} \mathrm{6:} \mathrm{TYMV} \mathrm{grafted} \mathrm{with}$ Au NPs via electrostatic bond; lane 7: ungrafted TYMV. Purple arrow: grafted TYMV. Red arrow: free AuNP. Blue arrow: ungrafted TYMV.

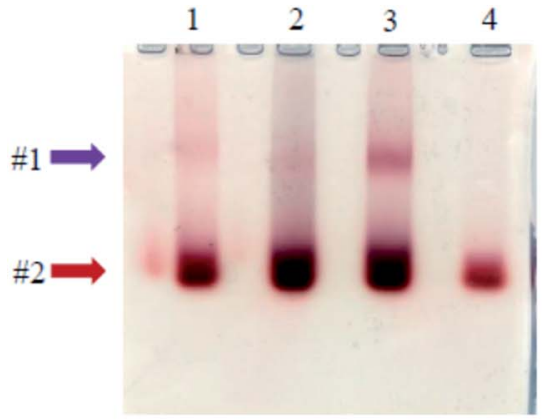

(a)

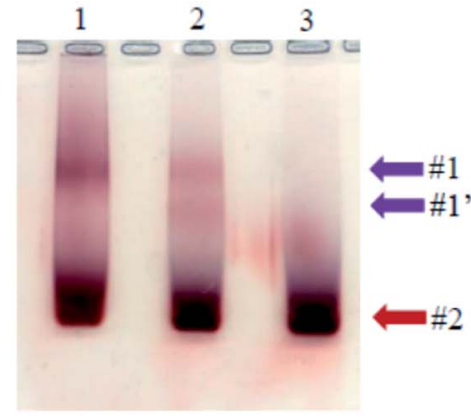

(b)

Fig. 6 Agarose electrophoresis of TYMV grafted with different ratios of AuNP : TYMV (a) lane 1-3: 20 nm-AuNP grafted onto $25 \mu g$ TYMV with the ratio of $10: 1,15: 1,20: 1$, respectively. lane 4: free $20 \mathrm{~nm}$-AuNP. (b) Lane 1, $2: 10 \mathrm{~nm}$-AuNP grafted onto $25 \mu \mathrm{g}$ and $50 \mu \mathrm{g}$ of TYMV to achieve the ratio of $30: 1$ and $15: 1$, respectively. Lane 3: free $10 \mathrm{~nm}$-AuNP. Purple arrow: grafted AuNP. Red arrow: free AuNP.

due to evaporation, the drop was then wiped off and the grid was allowed to dry overnight.

The covalent binding between AuNP and TYMV was confirmed with SDS-PAGE experiment. $40 \mu \mathrm{L}$ of 1000x concentrated grafted sample was incubated at $95{ }^{\circ} \mathrm{C}$ for 5 min with $10 \mu \mathrm{L}$ of loading buffer (10\% SDS, $10 \mathrm{mM} \beta$-mercaptoethanol, 20\% glycerol, $0.2 \mathrm{M}$ Tris-HCl pH 6.8, 0.05\% bromophenol blue) for the denaturation of the viral particles. The proteins were then resolved on a $15 \%$ polyacrylamide gel at $150 \mathrm{~V}\left(15 \mathrm{~V} \mathrm{~cm}^{-1}\right)$ for 3 hours in running buffer ( $25 \mathrm{mM}$ Tris-HCl, $200 \mathrm{mM}$ glycine, $0.1 \%$ SDS), followed by similar staining and destaining steps as for agarose gel.

\section{Surface enhanced Raman spectroscopy (SERS)}

The SERS experiments were performed in solution using a Labram HR800 micro-spectrometer, in backscattering configuration using an excitation line of $633 \mathrm{~nm}$ with a power of $5 \mathrm{~mW}$. The scattered light was collected with a long working distance objective of 100 -fold magnification (0.9 N.A.). The

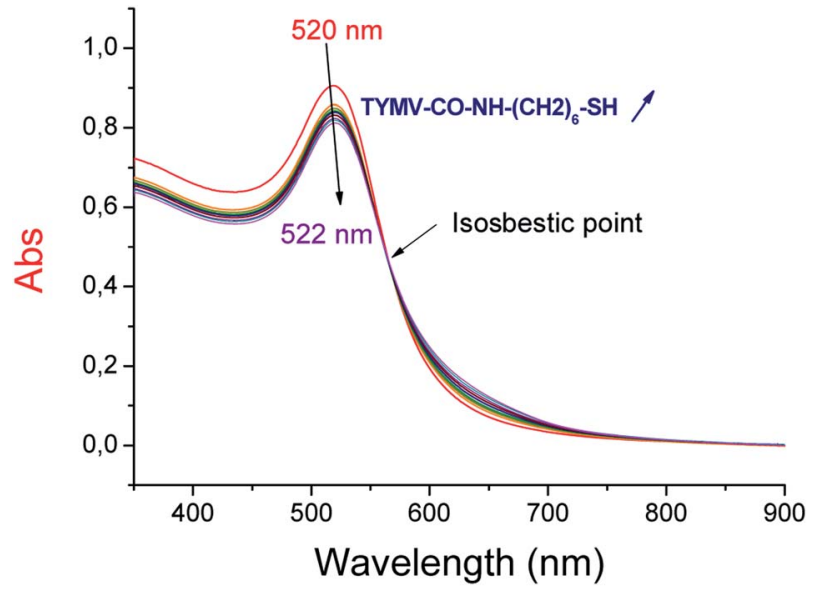

Fig. 7 Absorption spectra of $20 \mathrm{~nm}$-AuNP in the presence of increasing concentrations of TYMV coated by 6 -aminohexane-1-thiol. 


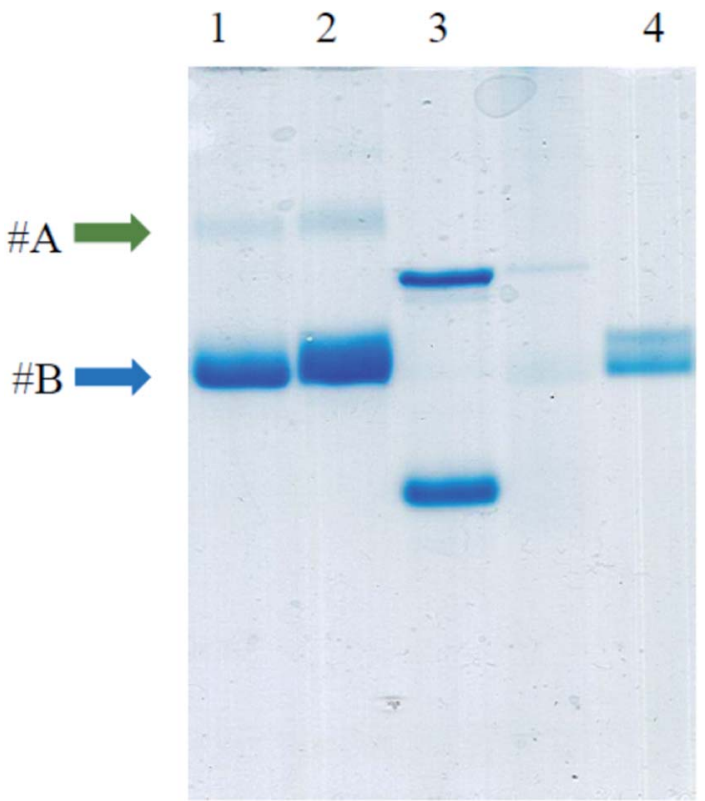

Fig. 8 SDS PAGE. Lane 1 \& 2: TYMV grafted with Au NP with concentration of TYMV (18 and $20 \mu \mathrm{g} \mathrm{mL}^{-1}$ in $5 \mathrm{~mL}$ of grafting solution, respectively); lane 3: molecular weight markers: trypsinogen (24 000 Da), $\alpha$-lactalbumin (14 200 Da); lane 4: TYMV. Green arrow: AuNP grafted TYMV capsid subunit. Blue arrow: ungrafted TYMV capsid subunit.

spectral resolution was less than $0.5 \mathrm{~cm}^{-1}$. The accumulation time for the SERS measurements was set to $3 \mathrm{~s}$ with three repetitions.

\section{Results and discussions}

\section{Characterization of TYMV and AuNp}

The extraction and purification of TYMV virus yields around $700 \mathrm{mg}$ per $\mathrm{kg}$ of infected Chinese cabbage leaves. DLS and TEM experiments show a capsid diameter of $28 \mathrm{~nm}$ (Fig. S3†), close to its reported value in the literature. ${ }^{12}$ The isoelectric point of the capsid was determined by measuring its $\zeta$ potential at different pH (Fig. 2) and found to be $3.5 \pm 0.1$, in agreement with the previously reported values. ${ }^{45,46} \mathrm{It}$ is consistent with the presence at the surface of many carboxylate groups from aspartate or glutamate residues. Indeed, there are 13 acidic amino acids per subunit of TYMV. These groups may offer the opportunity to react with amino groups to form amide bonds and to attach by this way amino modified AuNP (Strategy 1, Fig. 1). Such an approach was already successfully tested by Wang et al., for the attachment of fluorescein amine without affecting the capsid assembly. ${ }^{14}$

Otherwise, amino-alkyle-thiol molecules can be also used, as an alternative to site-directed mutagenesis, the amino group reacting with the TYMV carboxylate ones and the thiol one reacting with nude AuNP through Au-S bonding. Several studies had already demonstrated that grafting small molecules or even peptides did not alter the protein capsid. ${ }^{14-16}$ So, for this strategy, we used 6-aminohexane-1-thiol and we covalently bound it to TYMV capsid, in order to modify its surface and therefore allow it to interact with AuNP (Strategy 2, Fig. 1). We observed an increase of the isoelectric point value of this modified capsid compared to the unmodified one (from 3.5 to 8.4 for the un- and modified virus, respectively). As the $\mathrm{p} I$ value found is now close to the $\mathrm{p} K_{\mathrm{a}}$ values of thiol groups (Fig. 2), we then assumed that the surface of the capsid was modified and now exposes thiol groups.

In parallel, DLS and TEM measurements confirmed that we succeeded to synthetize, by the Turkevich route, spherical about 10 and $20 \mathrm{~nm}$ sized AuNP (Fig. S4†). These particles are mainly covered by citrate species (data verified by XPS experiments, but not shown), which can be easily replaced by 6aminohexane-1-thiol, the affinity of gold to thiols being higher to that of carboxylates. Adding this coating molecule leads to a red shift from 520 to $522 \mathrm{~nm}$ of the plasmonic band, and an isosbestic point at $624 \mathrm{~nm}$ (Fig. 3). Furthermore, DLS experiment of these cationic AuNP indicated (Fig. S4 $\dagger$ ) that the replacement of citrate by 6-aminohexane-1-thiol occurs without any aggregation.

The surface compositions of the Au NP before and after (6aminohexane-1-thiol) coating were investigated by XPS (Fig. 4). High resolution (HR) XPS spectra of Au 4 f (Fig. 4b) show $3.7 \mathrm{eV}$ splitting double peaks at about 83.6/87.3 and 83.9/87.6 eV for both citrate and 6-aminohexane-1-thiol coated AuNP, corresponding to $\mathrm{Au} 4 \mathrm{f} 7 / 2$ and $\mathrm{Au} 4 \mathrm{f} 5 / 2$ energy levels of metallic gold atoms, respectively. Moreover, the HR-XPS spectra of S $2 \mathrm{p}$ and $\mathrm{N}$ $1 \mathrm{~s}$ regions show the absence of any thiol or amine based species on citrate coated AuNP and their presence on those 6aminohexane-1-thiol coated ones. The recorded S 2p signal can be deconvoluted into three contributions at $161.9 / 163.1 \mathrm{eV}$, 164.0/165.2 eV and 167.9/169.1 eV, assigned to the S $2 \mathrm{p} 3 / 2$ and S $2 \mathrm{p} 1 / 2$ peaks of thiol in interaction with gold (grafted), free thiol and oxidized thiol, respectively, the major one being the first (Fig. 4c). The recorded $\mathrm{N}$ 1s signal is less complex and consists of a main peak at $400.0 \mathrm{eV}$ assigned to the amine/ammonium group $^{47}$ carried by the 6-aminohexane-1-thiol attached to AuNP (Fig. 4d). Altogether these results confirm the capability of the grafted AuNP to react with TYMV by amidation with its carboxylic/carboxylate groups. (a)

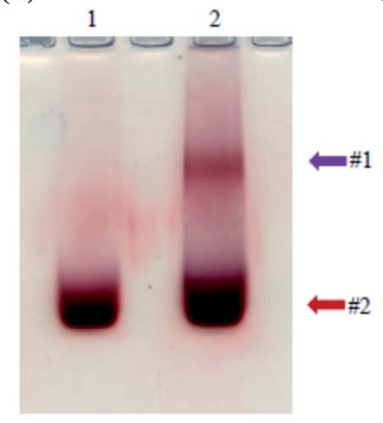

(b)

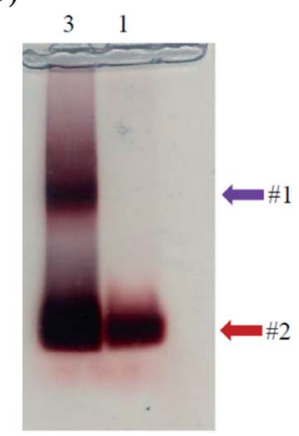

Fig. 9 Agarose electrophoresis of TYMV grafted with AuNP in optimum condition for (a) strategy 1 (lane 2), in comparison with free AuNP (lane 1) and (b) strategy 2 (lane 3). Purple arrow: grafted TYMV. Red arrow: free AuNP. 
(a)

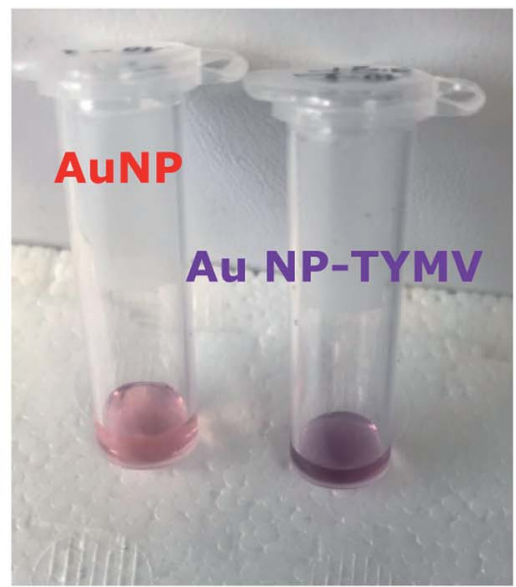

(c)

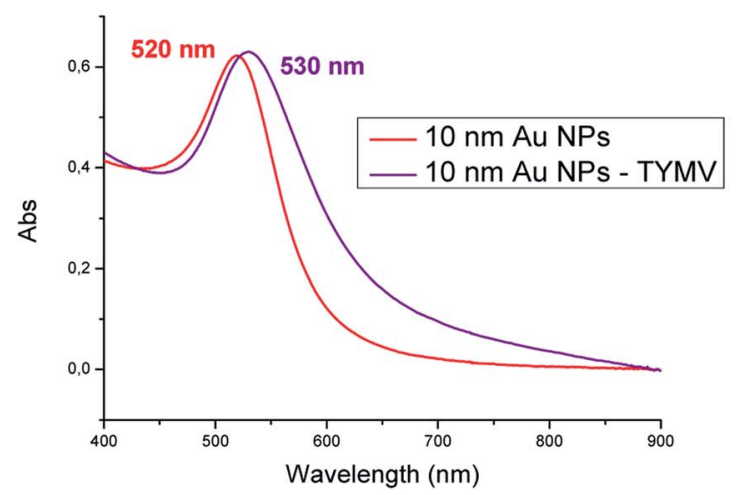

(b)

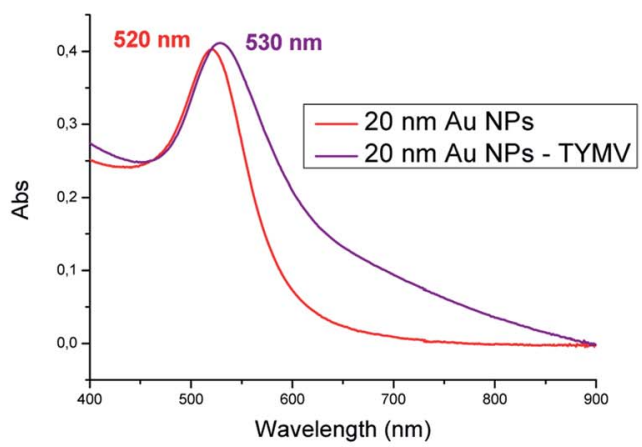

(d)

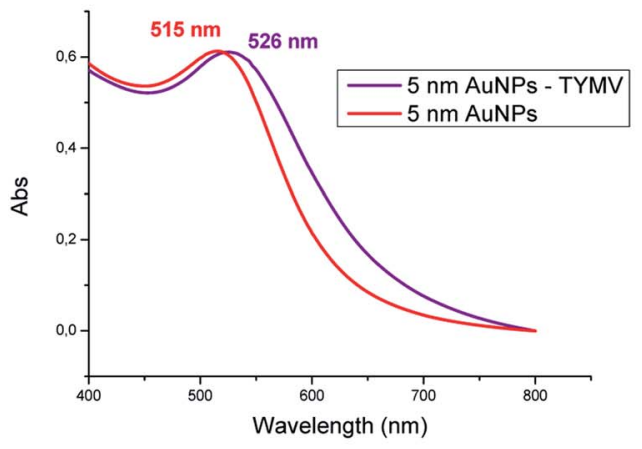

Fig. 10 (a) Picture of free AuNP (left side) and grafted to TYMV (right side) after gel purification. Absorption spectra of free AuNP (red) and grafted to TYMV for AuNP (violet) of (b) $20 \mathrm{~nm}$; (c) $10 \mathrm{~nm}$ and (d) $5 \mathrm{~nm}$.

\section{Optimization of the AuNP grafting onto TYMV}

Using strategy 1, functionalized AuNP were grafted onto the capsid of the virus via amide bonds by the activation of EDC with/without NHS in different experimental conditions. The grafting was analyzed by agarose gel electrophoresis. After the thioctic acid treatment, AuNP migrates to the positively charged anode, and separation is observed due to the difference in size. ${ }^{36}$ The slower migrating band (Fig. 5a, band \#1) corresponds to TYMV grafted to AuNP, while the faster migrating one (band \#2) corresponds to free AuNP. Staining with Coomassie Blue revealed a blue band corresponding to non-grafted TYMV capsid which migrates at an intermediate position (Fig. 5b, band \#3). The grafting experiments were carried in different media in order to determine the optimal experimental conditions for EDC activated amidation reaction. Even though the carboxylate activation by EDC shows high efficiency at $\mathrm{pH} 3.5$ to 4.5, EDC is unstable at those pHs due to its hydrolysis. Moreover, the amide bond formation reaches a maximal yield at a $\mathrm{pH}$ comprised between 4.0 and 6.0. ${ }^{48-50}$ Therefore, we decided to perform the grafting experiments at $\mathrm{pH}$ 5.5-6.0 with EDC as the only activator (lane 1 in MES buffer $0.1 \mathrm{M}$, lane 3 in phosphate buffer $10 \mathrm{mM}$ and lane 4 in acidic water). To increase the yield of this reaction, we also added NHS to EDC reaction. However, because the amidation of NHS-ester exhibits the highest efficiency at neutral or slightly alkaline $\mathrm{pH},{ }^{51,52}$ we adjusted the $\mathrm{pH}$ to 7.0 for the EDC/NHS activated reaction (lane 2 in phosphate

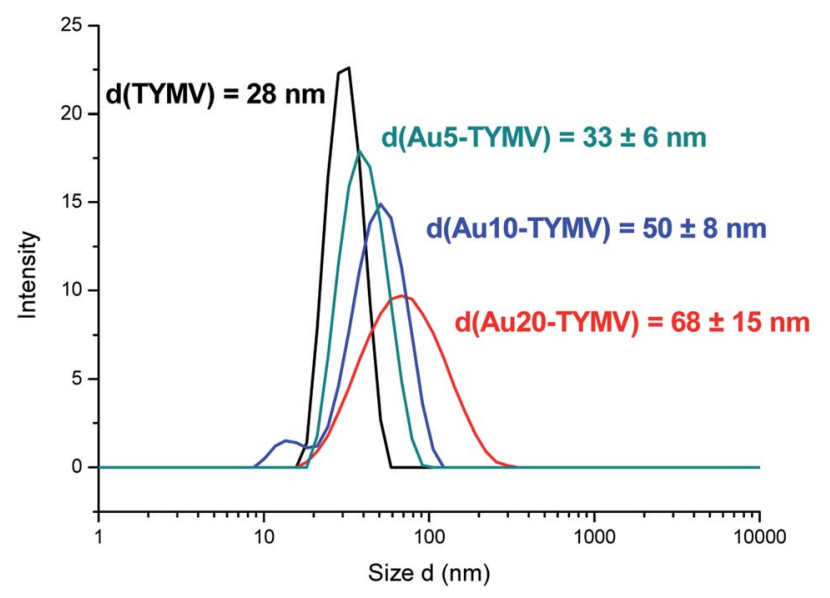

Fig. 11 DLS experiments. Particles size distribution of TYMV (black), TYMV grafted with AuNP of 5 (green), 10 (blue) and $20 \mathrm{~nm}$ (red). 
buffer $10 \mathrm{mM}$ ). Fig. 5a, lane 3 shows no migration of free or grafted AuNP probably due to aggregation during the grafting experiment. Indeed, some aggregations events are observed when the experiments were performed in buffer solution, indicating that the salts present in buffer may induce AuNP aggregation during the grafting reactions. In consequence and according to Fig. 5, the optimal condition for the synthesis and purification of the desired nano-bio-hybrid materiel is the carboxylate activation by EDC in acidic water, without NHS (lane 4).

We considered the most appropriate ratio of AuNP and TYMV to achieve the highest yield for the synthesis of the new materials. Fig. 6a shows agarose gel when we grafted the same amount of carboxylate activated TYMV $(25 \mu \mathrm{g})$ with 10,15 and $20 \mathrm{~mL}$ of $20 \mathrm{~nm}$-AuNP (lane 1, 2, and 3) corresponding to the ratio AuNP : TYMV of $10: 1,15: 1$ and $20: 1$, respectively. The gradual increase in the intensity of band \#1 from lane 1 to lane 3 shows that more grafted products were obtained using higher quantity of AuNP. Nevertheless, when using higher volume of AuNP (25 mL per reaction), AuNP aggregates during the concentration step. On the other hand, when the amount of carboxylate activated TYMV is increased from $25 \mu \mathrm{g}$ (Fig. 6b, lane 1) to $50 \mu \mathrm{g}$ (Fig. 6b, lane 2), another grafting band (band $\# 1^{\prime}$ ) with lower size compared to the initial one (band \#1) is obtained. It could be due to an incomplete TYMV grafting. Consequently, we used $25 \mu \mathrm{g}$ of TYMV and 20, 10 or $5 \mathrm{~mL}$ of $20 \mathrm{~nm}-, 10 \mathrm{~nm}$ - or $5 \mathrm{~nm}$-AuNP, respectively to obtain the best yield for the grafting experiments (Materials and methods).

For strategy 2, we performed the grafting experiment in water, considering the salt-sensitivity of the AuNP. Therefore, after the surface modification of TYMV with 6-aminohexane-1thiol, TYMV was washed with water using a $100 \mathrm{~K}$ concentrator to eliminate excess salts and coating molecule. Adding the modified TYMV to AuNP leads in the plasmonic band to a red-shift of $2 \mathrm{~nm}$ and an isosbestic point at $565 \mathrm{~nm}$ (Fig. 7). The ratio AuNP : TYMV was identical to that of the strategy 1.

The covalent bonds between AuNP and virus capsid were confirmed by performing SDS-PAGE experiment (Fig. 8). After treatment with $\beta$-mercaptoethanol at high temperature, TYMV

(a)
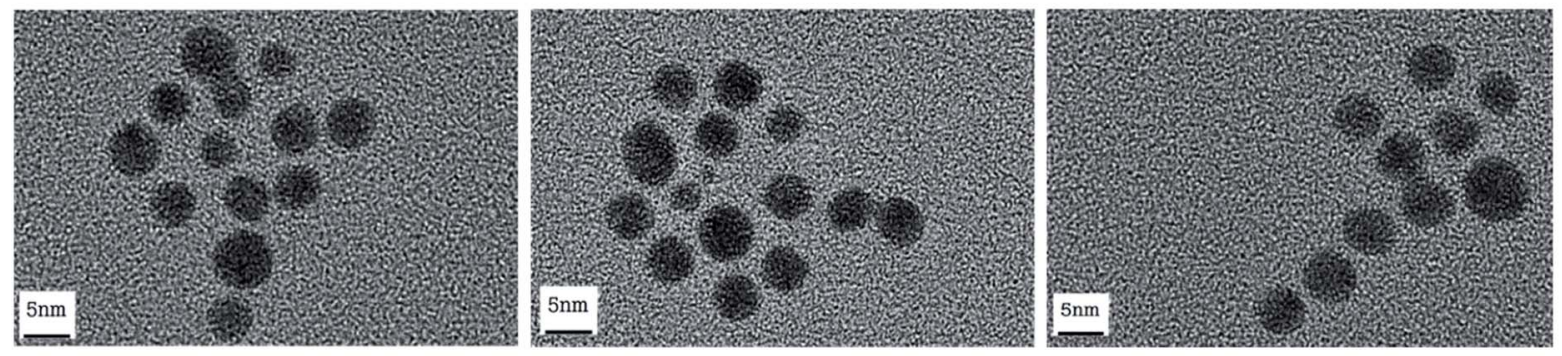

(b)
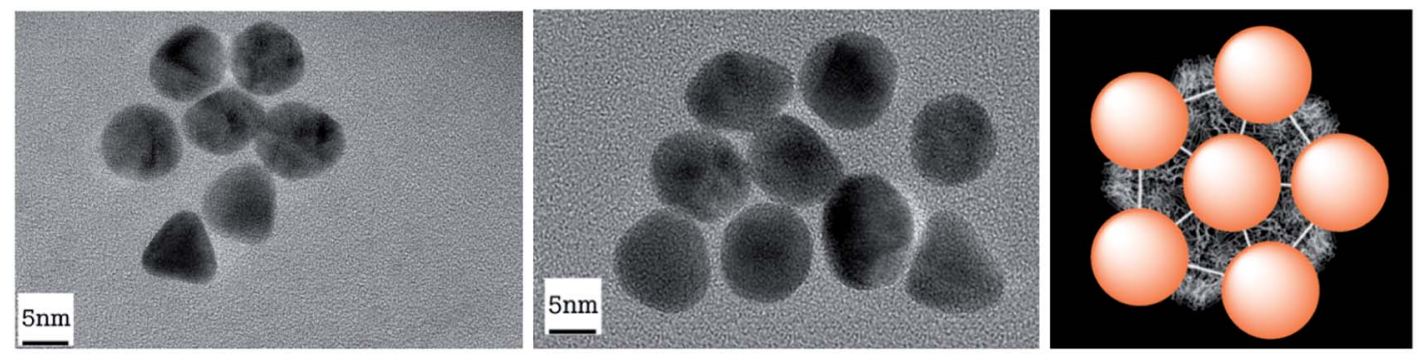

(c)
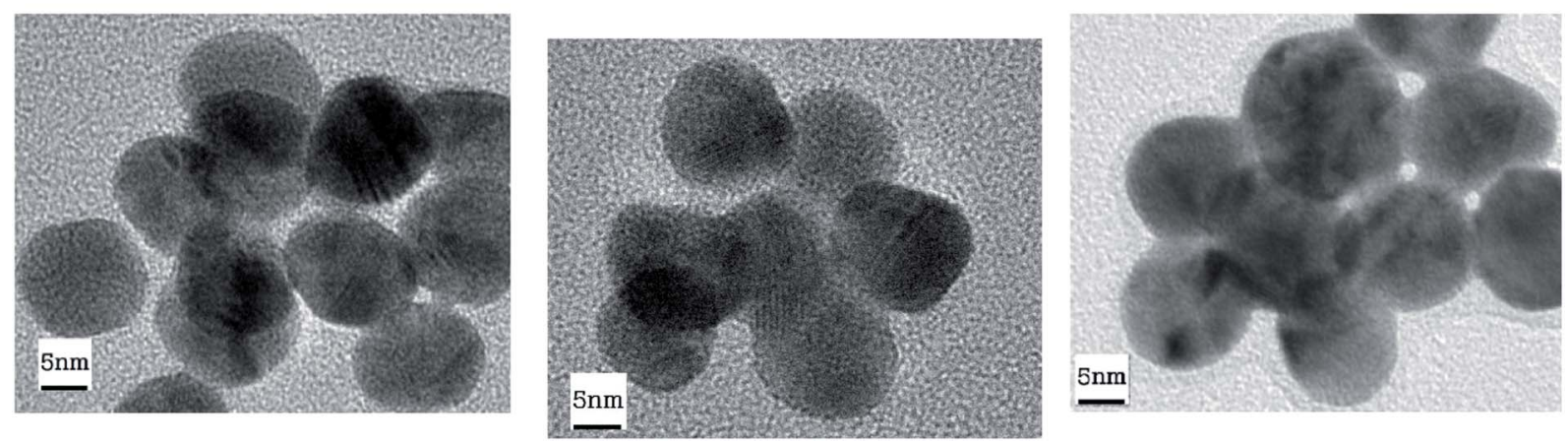

Fig. 12 TEM images of AuNP of 5 (a), 10 (b) and $20 \mathrm{~nm}$ (c) grafted to TYMV. (b) Model of TYMV grafted with AuNP. 
capsid is disassembled into identical subunits with a size of about $20000 \mathrm{Da}$ (lane 4, band \#B). This band was also observed in grafted samples (lanes $1 \& 2$ ) as an evidence for the presence of ungrafted TYMV capsid protein. However, a slower-migrating band was also observed (band \#A) for the grafted samples (lanes $1 \& 2$ ). This band represents an increase in size of TYMV capsid subunits after the grafting experiment. As the denaturing step at $95{ }^{\circ} \mathrm{C}$ breaks electrostatic bonds and that $\beta$-mercaptoethanol reduces disulfide bonds, we assume that this slower-migrating band corresponds to AuNP covalently bound to a protein subunit of the TYMV capsid.

Finally, with the optimal conditions found previously, we obtained the electrophoresis results without aggregation and a clear separation between the grafted (Fig. 9, band \#1) and ungrafted AuNP (band \#2) for both strategies. The new material was then purified using low-melting agarose gel and $\beta$ agarase. This step required to melt the gel at $70{ }^{\circ} \mathrm{C}$, before the digestion of agarose by the enzyme. Therefore, even though the grafting between TYMV and AuNP@6-aminohexane-1-thiol by electrostatic bonds showed high efficiency (Fig. 5a, lane 6), we only purified and characterized the nano-bio-hybrid materials synthetized with covalent bonds.

\section{Characterization of the new nano-bio-materials}

The material characterizations gave identical results after the synthesis according to strategy 1 or 2 . Therefore, the results are presented independently of the synthesis route. After purification, the solution of AuNP-TYMV exhibits a different color (purple), compared to that of the free AuNP with its characteristic red color (Fig. 10a). UV-visible spectra have been recorded to evaluate the changes induced in plasmonic AuNP band by the grafting onto TYMV. Free AuNP show a maximum band at $520 \mathrm{~nm}$ for the three different AuNP. When bound to TYMV, the plasmon bands are red shifted of 10, 10 and $11 \mathrm{~nm}$ for AuNP of 20, 10 and $5 \mathrm{~nm}$, respectively. Moreover, we noticed an enlargement of these bands, with the broader band for the larger AuNP (20 nm) (Fig. 10b-d). These spectral modifications have been also observed previously in the case of AuNP grafted onto CPMV, the UV-visible spectra exhibit a red shift in the plasmon absorption band and the appearance of a broad band in the 600-675 nm region. ${ }^{33}$ Furthermore, the growth of AuNP and their organization into the TMV lead to the widening of the plasmon band. ${ }^{39}$

Agarose gel indicated that AuNP-TYMV migrate slower than free AuNP, because of the higher size of the nano-object. DLS measurements then showed as expected an increase of the size of AuNP-TYMV compared to the virus capsid (Fig. 11). The hydrodynamic diameters are $33 \pm 6 ; 50 \pm 8$ and $68 \pm 15 \mathrm{~nm}$ for AuNP of $5 ; 10$ and $20 \mathrm{~nm}$ respectively. Similar results are observed with CPMV, when AuNP of $37 \mathrm{~nm}$ are covalently bond to CPMV, the major scattering peak in DLS experiments of this material is centered at $77 \mathrm{~nm}$.

TEM pictures show the arrangements of AuNP around the capsid (Fig. 12). The virus could not be stained by uranyl after AuNP grafting. However, these arrangements are not observed in the absence of virus (Fig. S5†). In the case of AuNP of $5 \mathrm{~nm}$
(Fig. 12a), it is possible to obtain virus with 7 to 12 grafted AuNP, as previously described. ${ }^{34}$ For bigger nanoparticles $(10$ or $20 \mathrm{~nm}$, Fig. 12b and c, respectively), the TEM pictures show a 5-fold axis symmetry, coherent with the icosahedral symmetry of the capsid. $^{33,35}$ As expected, the interspaces between the AuNP decrease with the size of AuNP (2-4 nm for $5 \mathrm{~nm}$-AuNP, 1-2 nm for $10 \mathrm{~nm}$-AuNP). Indeed, for the AuNP of $20 \mathrm{~nm}$ grafted onto the capsid, the nanoparticles are juxtaposed and probably create hot junction spots and could be then excellent substrates for SERS experiments.

Importantly, we obtained here a nano-bio-hybrid material that is highly soluble in water, with a zeta-potential value of $-44.2 \mathrm{mV}$. Moreover, after 3 months the materials present identical DLS and absorption spectra (Fig. S6 $\dagger$ ), and no aggregation of these objects was observed, indicating that these nano-objects also show high stability in water.

\section{SERS measurement}

We then performed SERS experiments in water with ungrafted or grafted onto the virus AuNP. For the comparison, we used solutions with the same absorbance at the maximum of the plasmon band (Abs $=0.4$ ), or with the same quantity of virus. 1,2-bis(4-pyridyl)ethane (BPE) was chosen as a probe molecule at a concentration of $10^{-5} \mathrm{M}$. Because the BPE should be adsorbed onto AuNP to give SERS signal, we used the nano-bio-hybrid material synthetized by strategy 2 . Indeed, in the presence of the nano-bio-hybrid material synthetized by strategy 1 , no SERS signal are observed (data not shown), we then assumed that BPE is not adsorbed because of the presence of 6-aminohexane-1-thiol onto the surface of our system, the AuNP are in strategy 2 recovered by citrate species which are less bound to gold than 6aminohexane-1-thiol. Free AuNP and in the presence of $0.24 \mathrm{mg} \mathrm{mL}{ }^{-1}$ TYMV show similar Raman spectra (Fig. S7†). The Raman bands of the proteins or RNA are not observed, probably because the virus is too large to be adsorbed at the hot spots of our system even at high concentration. ${ }^{53}$ This

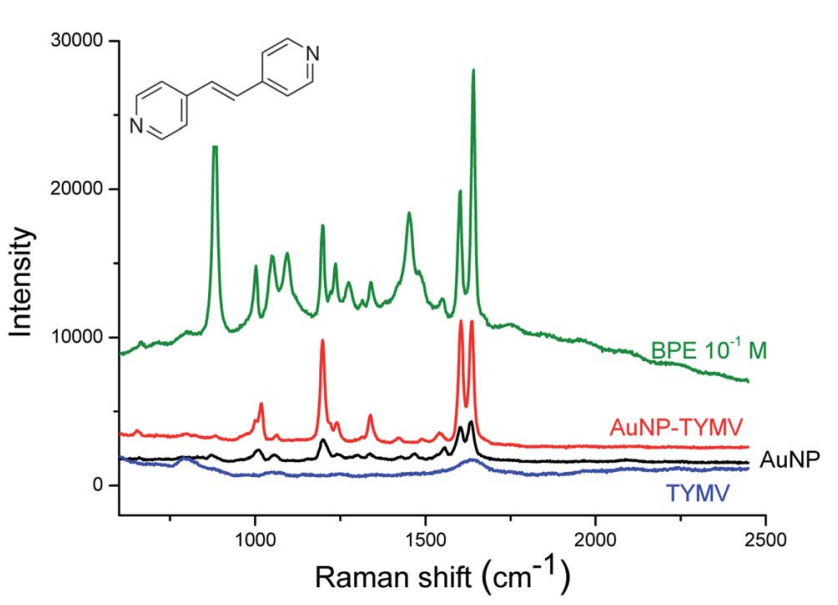

Fig. 13 SERS experiments. Raman spectra of BPE at $10^{-1} \mathrm{M}$ in solution in ethanol (green) and at $10^{-5} \mathrm{M}$ in the presence of TYMV (blue), 20 $\mathrm{nm}$-AuNP (black) and TYMV grafted to $20 \mathrm{~nm}$-AuNP (red). 
could explain that the Raman spectrum of AuNP grafted onto TYMV (with an estimated concentration of TYMV of $1 \mu \mathrm{g}$ $\mathrm{mL}^{-1}$ ) is identical to two previous spectra (Fig. S7†). Fig. 13 shows the Raman spectra of BPE in the presence of free TYMV, bare AuNP and AuNP-TYMV hybrids. In the presence of TYMV, only two bands around 800 and $1600 \mathrm{~cm}^{-1}$ are observed. With AuNP, these bands are slightly increased, with the appearance of two other peaks around $1000 \mathrm{~cm}^{-1}$ and $1200 \mathrm{~cm}^{-1}$, corresponding to the pyridine breathing and the in-plane ring modes, respectively. Interestingly, in the presence of AuNP-TYMV, the band at $1600 \mathrm{~cm}^{-1}$ was resolved, and two peaks appeared at 1639 and $1610 \mathrm{~cm}^{-1}$ corresponding to the $\mathrm{C}=\mathrm{C}$ stretching and the aromatic ring stretching modes, respectively. Furthermore, the intensity of each band was enhanced, indicating that this nano-hybridmaterial could be used as an in-solution sensor substrate. The band intensities increased with the concentration of BPE adsorbed (from $10^{-7}$ to $10^{-5} \mathrm{M}$ ) on our system (Fig. 14A). The plot of SERS intensity at 1600 and $1200 \mathrm{~cm}^{-1}$ against BPE concentration (Fig. 14B and C) show a quantification region (between $10^{-7}$ and $10^{-5} \mathrm{M}$ ) with a linear relationship, this can be expressed by $\log \left(I_{1600}\right)=(0.9) \times \log [\mathrm{BPE}]+8.6$ and $\log \left(I_{1200}\right)=(0.9) \times \log [\mathrm{BPE}]+8.7$. For BPE concentration higher than $10^{-5} \mathrm{M}$, the Raman intensity is constant or slightly decreases, which may be due to the saturation of BPE adsorbed on the SERS hot spots, or to the instability of the nano-bio-hybrid material at this high BPE concentration. The limit of detection of our system is estimated to $10^{-7} \mathrm{M}$ of BPE in solution. The analytical enhancement factors (AEF) are estimated from Fig. 13 and eqn (1) at $1 \times 10^{4}$ and $2 \times 10^{3}$ for AuNP-TYMV and free AuNP, respectively.

$$
\mathrm{AEF}=\left(I_{\mathrm{SERS}} / C_{\mathrm{SERS}}\right) /\left(I_{\mathrm{RS}} / C_{\mathrm{RS}}\right)
$$

with $I_{\text {SERS }}$, a SERS signal at $C_{\text {SERS }}$ concentration of BPE, $I_{\mathrm{RS}}$, Raman signal under non-SERS conditions at $C_{\mathrm{RS}}$ concentration of BPE.

Although the distance between the grafted AuNP was small enough to create a strong local electronic field, SERS experiments with the 10 and $5 \mathrm{~nm}$ sized AuNP grafted onto
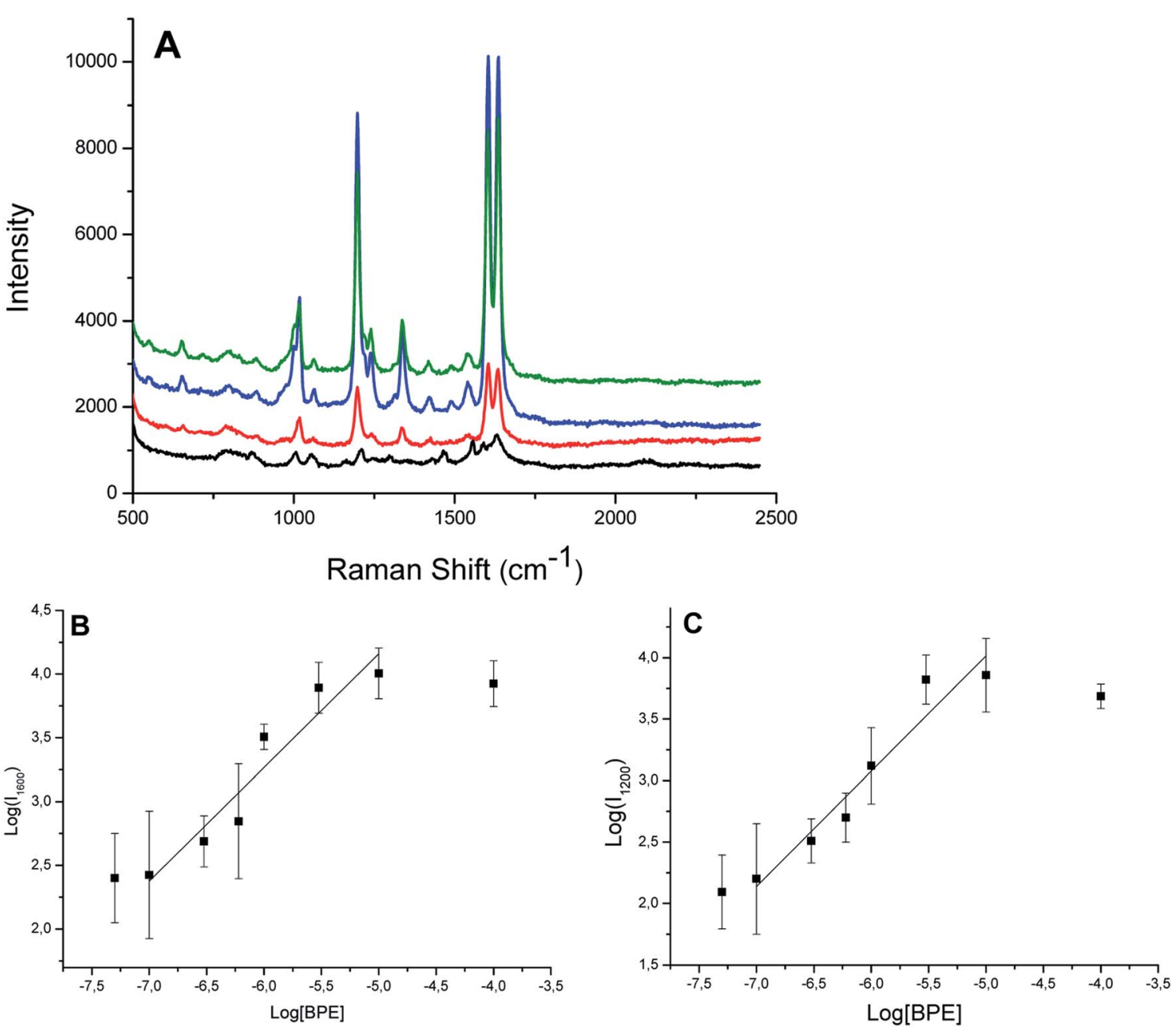

Fig. 14 (A) Raman spectra of BPE at $10^{-7}$ (black), $10^{-6}$ (red), $10^{-5}$ (blue) and $10^{-4} \mathrm{M}$ (green) in solution in the presence of AuNP-TYMV. The curves are shifted to better see the different curves. Plot of log of SERS intensity at $1600 \mathrm{~cm}^{-1}$ (B) and $1200 \mathrm{~cm}^{-1}$ (C) against log[BPE]. Errors bars correspond to standard deviations from $2-3$ experiments. (B) Slope, $(0.9 \pm 0.1)$; intercept, $(8.6 \pm 0.8) ; r^{2}=0.89$. (C) Slope, (0.9 \pm 0.1$)$; intercept, $(8.7 \pm 0.7) ; r^{2}=0.92$. 
TYMV did not show any enhancement of the Raman signals (Fig. S8†).

\section{Conclusions}

In this work, we used turnip yellow mosaic virus particles as a scaffold to arrange gold nanoparticles in 3D. For the first time, nano-objects were grafted to TYMV by covalent bonds with two different strategies. One is an alternative way to mutagenesis to introduce thiol function at the capsid surface. For large grafted AuNP, a 5-fold axis symmetry was observed consistent with that of the icosahedral capsid the new nano-bio-hybrid materials presented high solubility and stability in water, and SERS experiments performed in solution showed that they induced an enhancement of the Raman bands intensity of a probe molecule (BPE). These results are thus very promising for the development of ultrasensitive sensors in biological media, based on the addition onto the AuNP surface of biological molecules which could lead to specific and selective detections, and to improve the detection limit. Because we demonstrate here that TYMV capsid is appropriate for the grafting of gold nanoparticles, future experiments will aim at grafting onto TYMV viral particles other types of nanoparticles in order to enhance their intrinsic properties.

\section{Conflicts of interest}

The authors declare no conflict of interest.

\section{Acknowledgements}

ANR (Agence Nationale de la Recherche) and CGI (Commissariat à l'Investissement d'Avenir) are gratefully acknowledged for their financial support of this work through Labex SEAM (Science and Engineering for Advanced Materials and devices) ANR 11 LABX 086, ANR 11 IDEX 05 02. This research was supported by a PhD fellowship from the French Embassy in Vietnam. Patricia Beaunier is also sincerely thanked for her assistance during TEM experiments.

\section{References}

1 A. Kuzuya, M. Kaino, M. Hashizume, K. Matsumoto, T. Uehara, Y. Matsuo, H. Mitomo, K. Niikura, K. Ijiro and Y. Ohya, Polym. J., 2014, 47, 177.

2 S. Chakraborty, P. Joshi, V. Shanker, Z. A. Ansari, S. P. Singh and P. Chakrabarti, Langmuir, 2011, 27, 7722-7731.

3 D. S. Petrescu and A. S. Blum, Wiley Interdiscip. Rev.: Nanomed. Nanobiotechnol., 2018, 10, e1508.

4 L. Wang, Y. Sun, Z. Li, A. Wu and G. Wei, Materials, 2016, 9, 53.

5 I. Capek, Adv. Colloid Interface Sci., 2015, 222, 119-134.

6 J. N. Culver, A. D. Brown, F. Zang, M. Gnerlich, K. Gerasopoulos and R. Ghodssi, Virology, 2015, 479-480, 200-212.

7 F. Li and Q. Wang, Small, 2014, 10, 230-245.
8 Z. Liu, J. Qiao, Z. Niu and Q. Wang, Chem. Soc. Rev., 2012, 41, 6178-6194.

9 C. M. Soto and B. R. Ratna, Curr. Opin. Biotechnol., 2010, 21, 426-438.

10 V. Marjomaki, T. Lahtinen, M. Martikainen, J. Koivisto, S. Malola, K. Salorinne, M. Pettersson and H. Hakkinen, Proc. Natl. Acad. Sci. U. S. A., 2014, 111, 1277-1281.

11 M. A. Kostiainen, P. Hiekkataipale, A. Laiho, V. Lemieux, J. Seitsonen, J. Ruokolainen and P. Ceci, Nat. Nanotechnol., 2012, 8, 52 .

12 M. A. Canady, S. B. Larson, J. Day and A. McPherson, Nat. Struct. Mol. Biol., 1996, 3, 771-781.

13 S. Brenner and R. W. Horne, Biochim. Biophys. Acta, 1959, 34, 103-110.

14 H. N. Barnhill, R. Reuther, P. L. Ferguson, T. Dreher and Q. Wang, Bioconjugate Chem., 2007, 18, 852-859.

15 Q. Zeng, S. Saha, L. A. Lee, H. Barnhill, J. Oxsher, T. Dreher and Q. Wang, Bioconjugate Chem., 2011, 22, 58-66.

16 D. Kim, Y. Lee, T. W. Dreher and T. J. Cho, Virus Res., 2018, 252, 13-21.

17 S. Her, D. A. Jaffray and C. Allen, Adv. Drug Delivery Rev., 2017, 109, 84-101.

18 N. Elahi, M. Kamali and M. H. Baghersad, Talanta, 2018, 184, 537-556.

19 A. Gharatape and R. Salehi, Eur. J. Med. Chem., 2017, 138, 221-233.

20 E. Hussein, M. Zagho, G. Nasrallah and A. Elzatahry, Int. J. Nanomed., 2018, 13, 2897-2906.

21 K. Siddiqi, A. Husen, S. Sohrab and M. Yassin, Nanoscale Res. Lett., 2018, 13, 231.

22 K. Brach, M. Waszkielewicz, J. Olesiak-Banska, M. Samoc and K. Matczyszyn, Langmuir, 2017, 33, 8993-8999.

23 K. El-Nour, E. Salam, H. Soliman and A. Orabi, Nanoscale Res. Lett., 2017, 12, 231.

24 Z. A. Nima, A. Biswas, I. S. Bayer, F. D. Hardcastle, D. Perry, A. Ghosh, E. Dervishi and A. S. Biris, Drug Metab. Rev., 2014, 46, 155-175.

25 X. S. Zheng, I. J. Jahn, K. Weber, D. Cialla-May and J. Popp, Spectrochim. Acta, Part A, 2018, 197, 56-77.

26 N. Feliu, M. Hassan, E. Garcia Rico, D. Cui, W. Parak and R. Alvarez-Puebla, Langmuir, 2017, 33, 9711-9730.

27 J. Ou, H. Tan, X. Chen and Z. Chen, Nanomaterials, 2018, 8, 12.

28 Y. Chen, W. R. Premasiri and L. D. Ziegler, Sci. Rep., 2018, 8, 5163.

29 S. Kim, S. Lee, H. Y. Chi, M. K. Kim, J. S. Kim, S. H. Lee and H. Chung, Plant Pathol. J., 2013, 29, 105-109.

30 G. Yang, J. Nanda, B. Wang, G. Chen and D. T. Hallinan Jr, ACS Appl. Mater. Interfaces, 2017, 9, 13457-13470.

31 K. Bian, H. Schunk, D. Ye, A. Hwang, T. S. Luk, R. Li, Z. Wang and H. Fan, Nat. Commun., 2018, 9, 2365.

32 M. Bachelet and R. Chen, Chem. Commun., 2016, 52, 95429545.

33 N. Lebedev, I. Griva, W. J. Dressick, J. Phelps, J. E. Johnson, Y. Meshcheriakova, G. P. Lomonossoff and C. M. Soto, Biosens. Bioelectron., 2016, 77, 306-314. 
34 A. S. Blum, C. M. Soto, C. D. Wilson, J. D. Cole, M. Kim, B. Gnade, A. Chatterji, W. F. Ochoa, T. Lin, J. E. Johnson and B. R. Ratna, Nano Lett., 2004, 4, 867-870.

35 J. Fontana, W. J. Dressick, J. Phelps, J. E. Johnson, R. W. Rendell, T. Sampson, B. R. Ratna and C. M. Soto, Small, 2014, 10, 3058-3063.

36 C. M. Soto, A. S. Blum, C. D. Wilson, J. Lazorcik, M. Kim, B. Gnade and B. R. Ratna, Electrophoresis, 2004, 25, 29012906.

37 M. Wnęk, M. L. Górzny, M. B. Ward, C. Wälti, A. G. Davies, R. Brydson, S. D. Evans and P. G. Stockley, Nanotechnology, 2013, 24, 025605.

38 V. Liljestrom, A. Ora, J. Hassinen, H. T. Rekola, Nonappa, M. Heilala, V. Hynninen, J. J. Joensuu, R. H. A. Ras, P. Torma, O. Ikkala and M. A. Kostiainen, Nat. Commun., 2017, 8, 671.

39 K. Zhou, J. Zhang and Q. Wang, Small, 2015, 11, 2505-2509. 40 O. K. Zahr and A. S. Blum, Nano Lett., 2012, 12, 629-633.

41 D. Prod'homme, S. Le Panse, G. Drugeon and I. Jupin, Virology, 2001, 281, 88-101.

42 R. E. Matthews, Virology, 1960, 12, 521-539.

43 J. Turkevich, P. C. Stevenson and J. Hillier, Discuss. Faraday Soc., 1951, 11, 55-75.

44 A. Girard, H. Gehan, A. Crut, A. Mermet, L. Saviot and J. Margueritat, Nano Lett., 2016, 16, 3843-3849.
45 G. Kaur, J. He, J. Xu, S. Pingali, G. Jutz, A. Boker, Z. Niu, T. Li, D. Rawlinson, T. Emrick, B. Lee, P. Thiyagarajan, T. P. Russell and Q. Wang, Langmuir, 2009, 25, 5168-5176.

46 M. Fukuto, Q. L. Nguyen, O. Vasilyev, N. Mank, C. L. Washington-Hughes, I. Kuzmenko, A. Checco, Y. Mao, Q. Wang and L. Yang, Soft Matter, 2013, 9, 96339642.

47 J. F. Moulder, W. F. Stickle, P. E. Sobol and K. D. Bomben, Handbook of X Ray Photoelectron Spectroscopy: A Reference Book of Standard Spectra for Identification and Interpretation of Xps Data, Physical Electronics, 1995.

48 M. A. Gilles, A. Q. Hudson and C. L. Borders Jr, Anal. Biochem., 1990, 184, 244-248.

49 G. T. Hermanson, in Bioconjugate Techniques, ed. G. T. Hermanson, Academic Press, Boston, 3rd edn, 2013, pp. 259-273, DOI: 10.1016/B978-0-12-382239-0.00004-2.

50 N. Nakajima and Y. Ikada, Bioconjugate Chem., 1995, 6, 123130.

51 Y. G. Ko and P. X. Ma, J. Colloid Interface Sci., 2009, 330, 7783.

52 S. A. Madison and J. O. Carnali, Ind. Eng. Chem. Res., 2013, 52, 13547-13555.

53 X. Zhang, X. Zhang, C. Luo, Z. Liu, Y. Chen, S. Dong, C. Jiang, S. Yang, F. Wang and X. Xiao, Small, 2019, 15, e1805516. 